\title{
Para além e aquém de anjos, loucos ou demônios: CAPS e Pentecostalismo em análise
}

Beyond and Beneath Angels, Crazies and Demons: Mental Health Center and Pentecostalism Allende y aquende de los ángeles, locos y demonios: CAPS y pentecostalismo en análisis

\section{Luana da Silveira}

Universidade Estadual do Rio de Janeiro, Rio de Janeiro, RJ, Brasil

\section{Mônica de Oliveira Nunes}

Universidade Federal da Bahia, Salvador, BA, Brasil

\section{Resumo}

Este estudo coloca em análise modos de subjetivação da loucura, através das experiências dos usuários de um CAPS, nas religiões pentecostais, identificando possíveis articulações entre estas instituições. Trata-se de um estudo qualitativo, com o referencial da Análise Institucional e da Etnografia, realizado com quatro usuários filiados às igrejas pentecostais, seus familiares e equipe técnica do CAPS. Acredita-se que a relação entre o CAPS e a religião, se situa num campo de forças, enquanto modos de produzir saberes e fazeres sobre a loucura, sobre e com o louco. Esta tensão parece se acentuar na relação com determinadas religiões, como as pentecostais, que concebem a loucura como possessão demoníaca, mobilizando rituais de exorcismo. Paradoxalmente, se constatou a existência de uma lógica manicomial que perpassa as instituições, que produz subjetividades manicomiais, assim como se constatou que essas instituições também promovem inclusão social e produção de novos sentidos para a experiência da loucura.

Palavras-chaves: Loucura; Modos de Subjetivação; CAPS; Religião Pentecostal.

\begin{abstract}
This article analyses modes of subjectivation of madness in pentecostalism, through the experiences of psychosocial service (CAPS) users, and identifies possible articulations between these institutions. It is the result of a qualitative study, using institutional analysis and ethnography as its frame of reference, and was carried out with four users affiliated to pentecostal temples, family members and CAPS workers. It is generally believed that the relationship between mental health services and religion is set within a force field, as far as ways of producing knowledge and action about madness, on and with mad people, are
\end{abstract}


concerned. This tension appears to become stronger with some religious traditions, such as pentecostalism, that understand madness as demoniac possession, which mobilizes exorcism rituals. Paradoxically, our evidence shows the existence of an asylum logic that spans institutions, producing subjectivities typical of total institutions, but that those institutions also promote social inclusion and the production of new meanings for the experience of madness.

Keywords: Madness; Modes of Subjectivation; Community Mental Health; Pentecostalism.

\section{Resumen}

Allende y aquende de los ángeles, locos y demonios: CAPS y pentecostalismo en análisis. Este estudio analiza los modos de subjetivación de la locura, a través de las experiencias de los usuarios de un Centro de Atención Psicosocial (CAPS), en las religiones pentecostales; identificando posibles articulaciones entre estas instituciones. Se trata de un estudio cualitativo, que utilizó el referencial teórico del Análisis Institucional y de la Etnografía, realizado con cuatro usuarios afiliados a las iglesias pentecostales, sus familiares y el equipo técnico de CAPS. Se sostiene que la relación entre el CAPS y la religión se sitúa en un campo de fuerzas, en cuanto a los modos de producir prácticas y saberes sobre la locura; con y sobre el loco. Esta tensión parece acentuarse en la relación con determinadas religiones como la pentecostal, que conciben la locura como una posesión demoniaca, motorizándose rituales de exorcismo. Paradójicamente se constató la existencia de una lógica manicomial que traspasa las instituciones y que produce subjetividades manicomiales. Del mismo modo, se constató que esas instituciones también promueven inclusión social y producción de nuevos sentidos para la experiencia de la locura.

Palabras-claves: Locura; Modos de Subjetivación; CAPS; Religión Pentecostal.

\section{Introdução}

O presente trabalho se propõe a apresentar a pesquisa de mestrado pelo Instituto de Saúde Coletiva da Universidade Federal da Bahia, realizada entre 2006 e 2008 em um CAPS II- Centro de Atenção Psicossocial, de um município da Bahia (Silveira, 2008).
Parte-se do entendimento de que os CAPS devem operar sob a lógica da invenção, propondo novos discursos e práticas sobre a loucura, com a loucura e com o louco, em consonância com os pressupostos ético-estético-políticos da Reforma Psiquiátrica, engendrada pelo Movimento da Luta Antimanicomial, que primam pela desinstitucionalização e pela inclusão social. 
Assim, os CAPS precisam ser articuladores de uma rede de cuidado, produzindo interferências no cotidiano, no território, onde são mais potentes. Mas não basta abrir as portas, tirar as grades, habitar a cidade se as subjetividades manicomiais, que se apropriam e devoram a loucura, penetram a vida ao ar livre, aniquilando-a.

Com a territorialização dos CAPS, questões referentes à religião, sexualidade, violência entre outros, exigem sua inclusão nas ações desenvolvidas, engendrando diversos desafios. $\mathrm{O}$ que amplia o escopo tradicional da clínica, fazendo-a extrapolar os muros que obstruem a produção desejante da loucura.

Estes desafios estiveram presentes na experiência da autora enquanto psicóloga do CAPS $\mathrm{II}^{1}$, onde o tema da religião, sobretudo a evangélica, era trazido pelos usuários e familiares como referência ao modo como compreendiam a vida, o sofrimento e enfrentavam as questões cotidianas. Chamou a atenção a frequência do pronunciamento de frases como: "Jesus Te Ama”, “Jesus Me Ama, não é qualquer um”, "Só Jesus Salva”, "O Senhor é meu pastor, e nada me faltará", "Deus tem um plano especial pra mim", "Se for da vontade de Deus...", em referência clara à relação com o divino e explicitação de princípios do evangelho, invocando um Deus Amor, Salvador, Curador, Infalivel e Todo Poderoso. Também era comum ouvir referências às atividades religiosas em diversas igrejas enquanto modos de sociabilidade.

$\mathrm{O}$ que surpreendia eram as referências aos costumes tradicionais impostos por determinadas religiões, que incitavam comportamentos morais, como também rechaçavam modos de vida que não se enquadram nos preceitos religiosos. Ademais, o perfil proselitista do evangélico e o posicionamento de combate às religiões espiritualistas, especialmente as afrobrasileiras, bem como a compreensão da loucura enquanto possessão demoníaca, cujo mal teria que ser expulso, provocavam alguns desassossegos, pois iam de encontro aos princípios éticoestéticos e políticos que entendem a loucura como diferença que deve ser afirmada pelo seu caráter disruptivo.

À surpresa e ao desassossego, agregavam-se a curiosidade e o interesse em conhecer outras referências à religião que causavam estranhamento, principalmente sobre a possessão, o exorcismo, a glossolalia, a profecia e o louvor. Afetos que também eram mobilizados ao ouvir palavras como 
Demônio, Diabo, Satanás, Inimigo, enquanto representante de todos os males pessoais e sociais, encarnado no doido, drogado, veado, entre outros.

Assim, compreender a interface entre a saúde mental e a religião tornouse imperativo, tanto pela importância da religião na vida dos usuários $\mathrm{e}$ familiares, como pelo reconhecimento da religião enquanto agência terapêutica e recurso comunitário, na ótica e na experiência destes sujeitos. Deste modo, este trabalho parte do pressuposto de que a relação entre CAPS e religião situa-se num campo de forças, podendo reproduzir tensões históricas entre a ciência e a religião como modos de produzir saberes, fazeres sobre a loucura e sobre o louco. Esta tensão parece se acentuar na relação com determinadas religiões, como as pentecostais, que concebem a loucura como possessão demoníaca, o que mobiliza rituais para "expulsão do mal" (Andrade, 2002; Rabelo, 1993; Antoniazzi et al, 1994).

Para tanto, recortou-se como objeto de estudo modos de subjetivação da loucura através das experiências religiosas dos usuários de um CAPS II nas religiões pentecostais. A escolha do pentecostalismo $^{2}$ reside no seu reconhecimento como fenômeno contemporâneo emergente. Em poucas décadas as igrejas pentecostais alcançaram um contingente de adeptos, no Brasil, estimado entre 15 e 25 milhões de pessoas, migrados, predominantemente, do catolicismo (Espinheira, 2005). Também se observou que muitos usuários buscavam estas igrejas porque elas oferecem possibilidades de atendimento às questões práticas do cotidiano, desde a proposta de cura de doenças até soluções para problemas econômicofinanceiros e emocionais.

Alguns questionamentos perpassaram este estudo: o CAPS reproduz a tensão entre ciência e religião? Desconsidera a dimensão da religiosidade e a filiação a religiões como importantes no cuidado? A religião é considerada como recurso terapêutico/ comunitário? Quais são os modos de subjetivação engendrados em suas práticas? Os espaços religiosos pentecostais vão de encontro aos pressupostos da Luta Antimanicomial? Traduzem-se como espaços importantes para a construção de sentido da vida e para a compreensão do mundo? Contribuem para a estruturação de práticas cotidianas, promovendo suporte social? Favorecem a produção de novos sentidos à experiência da loucura? Configuram-se como modos de cuidado para as pessoas com sofrimento 
psíquico? Que subjetividades são produzidas nos interstícios destas instituições?

A análise se situa no campo da produção de subjetividade, constituído por um movimento ininterrupto, gerador de expectativa, aberta ao devir (Guattari \& Rolnik, 2000). Assim, colocam-se em análise modos de subjetivação da loucura através das experiências dos usuários do CAPS nas religiões pentecostais e como essas experiências são articuladas entre o serviço e estas religiões.

A contribuição deste estudo reside na análise micropolítica construída por estratégias voltadas para a produção de subjetividade, que se expressam no cotidiano dos serviços, transversalizadas com as macropolíticas, que se expressam muitas vezes em forma de decretos e portarias e de estratégias de conscientização, que não garantem, isoladamente, que novos modos de lidar com a loucura e com o louco possam se produzir. Estes planos se movimentam, se atravessam, são fluidos "são dois modos de recortar a realidade, são dimensões indissociáveis que, apesar de terem seus modos próprios de funcionamento, se infiltram uma na outra" (Neves \& Josephson, 2001, p.105).
Não basta imprimir modos de operar com a loucura no território, se as mentalidades manicomiais predominam nestas instituições. Precisamos de políticas de contágio "acolhendo sua alteridade, abrindo portas em todos os sentidos e desobstruindo a produção desejante" (Machado \& Lavrador, 2001, p. 47).

\section{Modos de caminhar e produzir encontros}

A partir do referencial da Análise Institucional- AI, esta pesquisa se delineou como um estudo qualitativo com enfoque etnográfico, realizado em um CAPS II na Bahia, como um estudo de caso.

As políticas públicas, muitas vezes, partem da premissa de necessidades universais, inequívocas e naturais das instituições sociais. A AI, em contrapartida, considera que as necessidades são forjadas historicamente, produzidas dentro de um contexto onde devem ser problematizadas. Diferencia o conceito de instituição como estabelecimento (CAPS/ igreja) do conceito de instituição como práticas sociais historicamente produzidas e tornadas naturais por um efeito de esquecimento 
das práticas de poder/saber (instituição loucura/instituição religião).

A etnografia, por sua vez, se propõe a tornar familiar o estranho, e estranhar $o$ familiar, num jogo incessante de aproximação e distanciamento para o conhecimento de uma dada realidade. O etnógrafo deve, então, imergir no universo do grupo ou cultura pesquisada.

A perspectiva da pesquisa foi de se deixar afetar pelo estranhamento, através da produção e afirmação de diferenças, marcadas pela interferência no processo.

Para tanto, foi realizada a observação participante ${ }^{3}$ dos modos de operar no CAPS, sobretudo analisando discursos acerca da religião, especialmente as pentecostais, permitindo se instalar nos interstícios das práticas, dos discursos não oficiais e das experiências cotidianas.

Foram realizadas entrevistas com quatro usuários do CAPS com diagnóstico de psicose, $\mathrm{sem}^{4}$ crise no momento da pesquisa, fiéis pentecostais, que foram acompanhados individualmente ou em grupo pela autora quando era psicóloga do serviço, sendo selecionados em discussão com a equipe do serviço; entrevistas com os familiares destes usuários e entrevistas com técnicos do CAPS. As entrevistas foram conduzidas através de um roteiro semi-estruturado, tendo como questões básicas para investigação o itinerário terapêutico e religioso e seus sentidos para a compreensão do seu sofrimento psíquico, modos de subjetivação da loucura, modos de entendimento dos familiares e técnicos sobre seu envolvimento religioso e possibilidades de articulação de práticas. Todas as entrevistas foram realizadas no CAPS, em dias que os usuários tinham atividades previstas, ou foram convidados a comparecer especialmente para participar da pesquisa. $\mathrm{O}$ mesmo aconteceu com seus familiares, sendo que foram entrevistados membros da família de três usuários, de um deles foi possível entrevistar apenas um membro de sua rede afetiva.

Os dados produzidos, através das entrevistas com os familiares, foram articulados com os dados produzidos a partir das entrevistas com os usuários, possibilitando a análise de discursos que se encontram e se separam através de distintas interpretações sobre a experiência do sofrimento, os cuidados terapêuticos e as experiências religiosas. As entrevistas com os usuários foram realizadas em dois momentos diferentes, com intervalos de seis meses, a fim de acompanhar o itinerário terapêutico e religioso. 
Realizou-se também grupo focal com os técnicos do CAPS, permitindo a produção de informações relevantes sobre os temas, possibilitando capturar discursos e os modos de produção dos mesmos, observação da interação e das relações de conflito e de poder.

A análise documental foi outro procedimento utilizado, buscando compreender como são elaborados os projetos terapêuticos singulares, identificando discursos presentes em prontuários, registros de atividades, entre outros.

\section{Vidas cruzadas}

Enredada por diversos nós, a trama das histórias compartilhadas engendra encontros e desencontros, de experiências atravessadas por alegrias, tristezas, medos, desejos, dúvidas, ousadias, realidades e delírios, que se mesclam num emaranhado de estranhamentos, desestabilizações, ambigüidades, rupturas e linhas de fuga. Buscando transversalizar as experiências, sentidos e modos de subjetivação, os dados produzidos foram discutidos em três eixos analíticos:

3.1. Modos de subjetivação da loucura; 3.2. Modos de subjetivação da religião;
3.3. Modos de cuidado: limites e possibilidades de articulação do CAPS com o espaço religioso pentecostal;

Colocar em análise as instituições implica no reconhecimento de seus fluxos capturados e em curso que movimentam e/ou a conservam, identificando e fazendo eclodir crises, emergência dos analisadores, permitindo analisar as transversalidades e implicações. A análise das implicações busca dar visibilidade às relações dos participantes, incluindo o próprio pesquisador, com as instituições que se atualizam na intervenção. Assim, transversalizar as análises reside em iluminar as instituições atravessadas nas práticas.

\subsection{Modos de subjetivação da loucura - como dizer o indizível}

Para começar há que se destacar que a palavra loucura não aparece nos discursos como um modo de entendimento da experiência disruptiva do sofrimento psíquico. Tal ausência aponta para a negativização do sentido da loucura, marcada por preconceito e estigma, constituindo-se como um analisador do emudecimento da loucura, que foi rechaçada como fonte de alguma verdade num processo iniciado no século XVII, com contraposição entre 
razão e desrazão. Os loucos emudecidos e excluídos têm sido, deste então, os representantes da escória da humanidade, como um mal a ser banido/ curado (Pelbart, 2001; Birman, 2002; Foucault, 2005).

Loucura interditada - em seu lugar aparece a depressão no discurso de todos os usuários entrevistados. Neste sentido, a justificativa que uma das entrevistadas encontra para denominar seu sofrimento psíquico como depressão "eu falo só na depressão, depressão todo mundo tem, né?" (sic) sintetiza o modo como esse sofrimento aparece na contemporaneidade, denotando a proliferação do mal-estar por um lado, e por outro, uma psicopatologização da vida.

Entretanto, o sentido da depressão também evidencia uma maior aceitação social, pois como foi apontado: "até mesmo Jesus Cristo teve depressão no momento em que se sentiu desamparado" (sic).

É interessante ressaltar que se trata de uma nova roupagem sobre o modo como tradicionalmente as classes populares significam a loucura como "doença dos nervos". Outro analisador é o significado da loucura como psicose não identificada, que não apareceu nas entrevistas e nas conversas com os técnicos, mas pôde ser identificado nos prontuários, como diagnóstico de três sujeitos. Isto aponta para a complexidade e consequente dificuldade em enquadrar a loucura na classificação nosológica.

Todavia, os significados que emergem na maioria dos discursos são o de doença psiquiátrica e transtorno mental. Termos analisadores que corroboram com o modelo hegemônico que reduz a loucura à doença mental. (Amarante, 1995).

A loucura como doença também aparece no discurso de três usuários, "Eu estou consciente de que é um problema né, uma doença psiquiátrica (sic)". Apenas um dos entrevistados faz o contraponto "eu não tenho problema mental não. Problema né, como é que fala? Da mente desde nascença tenho não (...). Problema da alma, problema de tristeza" (sic).

Para os familiares, mesclam-se os significados de doença e problema espiritual, menos para os filhos de uma das usuárias que relacionam o sentido de doença ao cotidiano e às relações familiares como geradora de sofrimento.

Outro modo de subjetivação da loucura é como possessão demoníaca. Embora o pentecostalismo enuncie a loucura desta forma, aparece 
significativamente apenas em dois casos. O modo de subjetivar a loucura não passa pelo significado da doença, mas como um problema espiritual, em que a depressão é vivida como uma intervenção demoníaca: “demônio coloca a tristeza na pessoa, as coisas, a doença na pessoa, quando ele vive até ao redor da pessoa" (sic); "o mal é o diabo que fica me falando" (sic).

Contudo, outra entrevistada coloca que mesmo no momento em que se sente atormentada pelos delírios persecutórios, não atribui à possessão demoníaca. "Mas o pessoal, esse pessoal evangélico é um pessoal diferente. É um pessoal diferente, eles invocam muito assim, diz muito, fala muito em demônio, essa coisa toda" (sic).

Para os familiares entrevistados, embora todos sejam pentecostais, este significado não aparece, sendo um analisador que evidencia o modo como o significado hegemônico de doença atravessa a maneira de entendimento dos familiares e se sobrepõe a outros significados.

Os técnicos tecem críticas ao significado de possessão, sendo uma das principais divergências em relação às religiões pentecostais: “(...) algumas alucinações auditivas e visuais ser confundidas com uma questão muito demoníaca né, que isso é uma coisa, que isso não faz parte de um adoecimento mental, mas sim do inimigo né, que termina de uma certa forma atrapalhando o nosso trabalho"(sic).

Neste eixo surpreendeu a ausência de categorias sobre a loucura, como diferença, desrazão, estranhamento, que afirmam a experiência da loucura. Trata-se de um analisador que aponta para a necessidade de direcionarmos nossos olhares "para os ideais que 'pairam' acima de nossas cabeças e ocupam nossa imaginação, como assombrações que nos exortam" (Fonseca, 2004, p. 32). E assim, nos acompanham nas práticas de produção de saúde e cuidado, oferecendo o risco de institucionalizar a loucura com novos dispositivos. Falamos dos manicômios mentais (Pelbart, 2001), engendrados por um agenciamento coletivo do tipo “capitalístico" (Guattari \& Rolnik, 2000), tanto do ponto de vista epistemológico, assistencial e jurídico, quanto cultural, que interrompe e obstrui a produção desejante da loucura. 


\subsection{Modos de subjetivação da} religião

A presentificação da religião na vida dos quatro usuários se mostra de modo significativo, evidenciando a matriz religiosa familiar e a inserção no espaço religioso desde a infância, sendo que dois sujeitos migraram do catolicismo para o pentecostalismo, enquanto que os outros dois são evangélicos desde a infância. Em todos os casos o itinerário religioso aparece, característica comum entre pentecostais (Andrade, 2002).

Para dois sujeitos, a religião emerge como principal modo de subjetivar a loucura, aparecendo como agência terapêutica, pois oferece um idioma que propicia um ordenamento para a experiência disruptiva ao denominá-la como possessão, sendo um analisador.

A religião também propicia um ritual de cura, através do exorcismo, que consiste em expulsar o demônio por meio de orações e da imposição das mãos sobre o indivíduo que está possuído, como indica este relato:

Chamam as pessoas na frente pra orar (...) Começa a orar, impõe as mãos na cabeça é, coloca as mãos, vira, coloca as mãos pra cima, pra orar pra, expulsar, chamar pelo sangue de Jesus. Coloca a mão na cabeça da pessoa, ora e faz a oração "demônio, sai o demônio, manifesta!”. (sic)

A crença na cura denota que ela acontece na medida em que o sujeito se liberta da possessão do demônio, enquanto representante do mal que o aflige, como pode ser visto: “ $E$ $o$ espírito do mal vai saindo da pessoa, a pessoa se liberta (...). Libertação da alma. (...) É coloca a mão na cabeça pra expulsar o, os, expulsar o diabo (...). Eu fecho os olhos, começo a orar. Eu caio no chão e aí o mal foi embora”. (sic)

Conforme Rabelo (1993), a importância dos cultos religiosos, enquanto agências terapêuticas das classes populares urbanas têm sido amplamente reconhecidas, através da análise das diferentes estratégias pelas quais as religiões reinterpretam a experiência da aflição e produzem mudanças no modo pelo qual o doente e a comunidade em que está inserido percebem o problema.

No entanto, outra entrevistada, que está há cerca de 2 anos numa igreja pentecostal renovada, não compartilha com o universo simbólico do ritual religioso de sua igreja, porque provoca estranhamento e medo, mas também 
fascínio, uma vez que o ritual desta igreja difere significativamente da sua igreja de batismo, a Igreja Batista Tradicional. Para ela, a religião se constitui como rede social que propicia a inclusão social, sendo, portanto, um analisador dos diversos sentidos da experiência religiosa. $\mathrm{O}$ que é reiterado pelos filhos, que migraram com ela para a Igreja Renovada no momento em que a Igreja Batista Tradicional falhou enquanto espaço de inclusão social e eles se sentiram forçados a mudar de igreja, tendo sido acolhidos em uma neopentecostal. Segundo Hulda Stadtler (2002) após a conversão para o pentecostalismo, as pessoas se percebem diferentes, principalmente devido aos vínculos comunitários, sentimentos de pertinência, papéis desempenhados, percepções do mundo para fora do grupo religioso.

Uma das entrevistadas, a única adepta de uma religião representante da primeira onda - a face tradicional do pentecostalismo, a religião apresenta um modelo de e para a realidade, incitando padrões morais de comportamento (Geertz, 1978). A religião, enquanto sistema simbólico é público e centrado no ator, que o usa para interpretar seu mundo e para agir, de forma que também o reproduz. As interações sociais são baseadas numa realidade simbólica que é constituída de, e por sua vez, constitui os significados, instituições e relações legitimadas pela sociedade.

É a gente orando, é bom, não é ruim
não, melhor assim do que no mundo
pra perdição né, não? Nas drogas
igual muitos, que fica nas droga, é pior
ainda. Melhor ir pra uma igreja assim,
evangélica mesmo, de que no mundo,
em outro mundo das drogas ou
pintando os escambaus igual tem
muitos (... )" (sic)

Todavia, a religião para ela não se constitui como agência terapêutica. Embora aborde o espaço religioso como "um lugar para onde ir" nos momentos em que se sente sozinha, sua relação com a religião Congregação Cristã no Brasil é ambígua, uma vez que se sente discriminada pelos fiéis e apresenta dificuldades para se enquadrar dentro dos preceitos religiosos. Contudo, após a tentativa do suicídio, a busca da religião tem se dado como um modo de garantir a salvação, através do arrependimento e da fé, sendo estimulado pela família.

Embora os modos de subjetivar as experiências religiosas sejam diferentes, todos acreditam na Santíssima Trindade: Pai, Filho e Espírito Santo e procuram Deus no 
momento de aflição, revelando uma relação transcendental com o divino, em que a religião se constitui como mediadora desta relação, assumindo importância em suas vidas. A crença em um Deus Todo-Poderoso, Infalível, que Cura, que Salva e que Ama perpassa o modo de lidar com a vida, com as situações de dor e aflição, sentindo-se amparados, protegidos e perdoados.

A recorrência à religião em momentos de sofrimento, doença é comum em nossa sociedade e ocorre em muitas situações em que os modelos tradicionais de cuidado não conseguem resolver todos os problemas demandados (Rabelo, 1993; Espinheira, 2005; Redko, 2004; Vasconcelos, 2006; Montero, 1985; Nunes, 1999; Dalgalarrondo, 2006; Andrade, 2002; Baltazar, 2003; Antoniazzi et al, 1994). Ademais, as igrejas pentecostais oferecem um ritual mágico, com cantos, danças que expressam intensas emoções, o que mobiliza a adesão de fiéis, assim como a ênfase em donsprofecia e glossolalia, produzem encantamento e fascínio sobre as pessoas, como foi evidenciado em todos os casos.

Para os familiares entrevistados a religião não aparece diretamente como agência terapêutica. Os filhos de uma das usuárias se posicionam categoricamente, diferenciando os espaços terapêuticos dos religiosos, não vislumbrando possibilidades de que a religião possa produzir a cura, mas ressaltam o papel de rede social.

\begin{abstract}
Eu acho que pode ajudar, mas não tratar. É porque na igreja você tá convivendo com outras pessoas né (...) isso pode ajudar bastante, mas curar assim, eu acho que, além disso, tem que ter o tratamento. A mesma coisa é você falar assim "tô com o braço quebrado, eи vou na igreja que eи vou curar". Acho que não tem nem lógica (sic).
\end{abstract}

Apesar da presença da temática da religião, sobretudo as evangélicas, no cotidiano do CAPS, a perspectiva dos técnicos é de negativização e negação da experiência religiosa dos usuários, senso um analisador. Tecem críticas ao modo como determinadas religiões oferecem um padrão rígido de comportamento moral, gerando conformismo, resignação e uma crença no determinismo. Ademais, apontam que a dificuldade maior é com as igrejas evangélicas.

Apesar de ter sido criada, e meus pais fazem parte da igreja católica, não freqüentadores assiduamente, mas é, hoje em dia eu não freqüento nenhum 
espaço religioso e devo confessar que tenho um pouco de resistência aos protestantes, a religião... Mas tenho trabalhado muito nisso por conta que a grande maioria dos usuários aqui do serviço são de religiões protestantes. (...) Por questões pessoais mesmo, acho que por não aceitar, por questionar diversas coisas, eu, são colocadas, diversos pensamentos que são colocados nessa religião... Então assim, é... Ultimamente eu tenho tido uma aproximação maior, mas até por boa parte da minha vida não tinha tido contato com ninguém que freqüentasse essa religião, essa igreja e que fosse do meu convívio diário. Então hoje eu percebo, e assim me parece que há uma imposição muito grande das questões da bíblia, há proibições e que às vezes a pessoa se submete sem nem entender o porquê daquilo. Então eu não concordo muito né, com esse tipo de conduta, mas tenho procurado não deixar interferir nos atendimentos". (sic)

Esta fala é um analisador do conflito cultural, pois dentre os técnicos apenas uma é de matriz evangélica, sendo que os demais tiveram dificuldades em caracterizar as religiões evangélicas pentecostais, apresentando dificuldades em distinguir as religiões tradicionais das neopentecostais. De acordo com Rabelo (1993), para que o tema seja reconhecido e abordado é importante que se compartilhe o universo

simbólico.

$\mathrm{O}$

desconhecimento, o preconceito, as crenças pessoais e, sobretudo, o atravessamento das concepções tradicionais em saúde sobre a religião, favorecem para a negação e a negativização da experiência religiosa. Salienta-se que os argumentos para tal visão não foram pautados nos princípios e diretrizes da Reforma Psiquiátrica. $\mathrm{O}$ modo como a equipe técnica aborda a religião corrobora com diversos estudos que denotam haver uma tensão entre os campos da saúde e religioso sobre modos de entender e lidar com fenômenos envolvendo saúde/doença e cuidado, principalmente sobre o sofrimento psíquico e a loucura (Espinheira, 2005; Vasconcelos, 2006; Baltazar, 2003; Machado, 2001). Entretanto, há o reconhecimento de que a religião para algumas pessoas se constitui como modo de inclusão social, favorecendo a melhora da situação disruptiva de sofrimento psíquico, denotando que as posições não são unívocas e homogêneas.

Então, teve alguns pacientes que, após começarem a freqüentar determinada religião, e fazerem amigos e terem uma vida social mais ampla, porque antes viviam apenas em casa ou não tinham amigos ou não tinham relações, se sentiram bem melhor. Então, mais 
casos de depressão ou de isolamento social. (...) Existem alguns usuários que, por conta da religião, por se sentirem acolhidos, fazerem parte de um grupo social, têm uma melhora relevante (sic).

Tanto nas conversas informais, como no grupo focal e nas entrevistas, os discursos apenas surpreenderam por serem respostas clássicas que enquanto era integrante da equipe não tinham tanta visibilidade até porque compartilhava de algumas concepções e modos de lidar com o tema da religião sendo analisador do caráter de reprodução histórica de discursos instituídos da ciência contra a religião.

\subsection{Modos de cuidado em saúde}

mental: limites e possibilidades de articulação do CAPS com o espaço religioso pentecostal

Adentraremos agora na discussão sobre modos de cuidado, colocando em análise modos instituídos e instituintes de atenção à loucura, ao louco, identificando limites e possibilidades de articulação entre o CAPS e o espaço religioso pentecostal, através de dramas e tramas que se enredam e se entrecruzam nos cuidados terapêuticos tradicionais, da atenção psicossocial e do cuidado religioso.
Todos os usuários da pesquisa carregam a marca do modelo manicomial em seu itinerário terapêutico, sendo que todos tiveram passagem pelo ambulatório de Psiquiatria, sendo um analisador. Esta necessária passagem pelo ambulatório denuncia uma estratégia assistencial que materializa a possibilidade de gerir a terapêutica centrada no atendimento médico e na psicofarmacologia, sem necessitar do hospital (Dimenstein \& Alverga, 2005).

Dois usuários também são marcados pela experiência enlouquecedora da internação em Hospital Psiquiátrico, que em um dos casos, ocorreu mesmo após estar sendo acompanhado pelo CAPS. Apesar de tecerem críticas a este modelo, apontam para o caráter imprescindivel da necessidade do hospital nos momentos de crise, sendo reiterado pelos seus familiares. A necessidade do manicômio é reforçada pela dificuldade apresentada pelo CAPS em abordar a crise, encaminhando alguns usuários para internação psiquiátrica, o que é analisador da fragilidade da rede de saúde no cuidado integral neste município, uma vez que não possui leitos no hospital geral e nem um CAPS III, que poderiam prestar um cuidado mais intensivo no momento da crise, e 
não existe uma articulação com a rede social.

A recorrência ao hospital, como o velho caminho da roça trilhado há séculos, nos momentos de intensificação do sofrimento psíquico, é analisador das dificuldades em construir as políticas públicas de saúde mental que se materializam no CAPS e na rede de saúde, para que novos entendimentos e práticas sobre a loucura e com o louco surjam. É também um analisador da lógica alternativa que permeia o processo de implantação da mudança de modelo de atenção em saúde mental. Se, por um lado, a Política Nacional incentiva a expansão da rede de serviços comunitários e territoriais, centrando na estratégia CAPS, por outro, o fechamento dos hospitais psiquiátricos, após o processo de redução progressiva de leitos, ainda se constitui como um futuro longínquo, quase inalcançável, não havendo clareza nem um planejamento definido. Tal lógica denuncia o funcionamento da rede que deveria ser substitutiva e se apresenta enquanto rede alternativa e complementar ao hospital psiquiátrico, como fora colocado pelos entrevistados.

$\mathrm{Na}$ medida em que a lógica manicomial hospitalocêntrica se presentifica nos serviços substitutivos e se espraia pelas cidades, escancara modos de subjetivação contemporâneos eivados por "desejos de manicômios" (Machado \& Lavrador, 2001), que capturam e mortificam a loucura (Dimenstein \& Alverga, 2005).

Nas histórias de dois entrevistados, o CAPS não aparece enquanto um modo de cuidado no momento da crise, a qual é entendida como uma realidade subjetiva e coletiva, que perpassa o sujeito e as instituições, atravessadas pelas dimensões familiar, econômica, social, cultural, política, histórica, antropológica, sexual, afetiva, ética, estética, entre outros.

A pessoa em crise, deste modo, é um estranho. Este estranhamento é também, por sua vez, um fecundo analisador, que "encobre e revela a potência instituinte da crise que fala da caduquice do instituído (...)”. É a força da autoprodução, é a captura e é a reprodução autofágica de traços de identidades anteriores, vistas ou vividas (Bichuetti, 2005, p. 27).

Além disso, o CAPS apresenta dificuldades em lidar com as questões do cotidiano de uma das entrevistadas, com sua diferença, inquietude e movimento de recusa em aderir aos projetos terapêuticos impostos pelo serviço. A equipe se mostra incomodada também com seu pai, uma vez que ele, 
ao mesmo tempo em que legitima o atendimento médico, o desautoriza, ao alterar as medicações sem conversar com os profissionais do serviço.

Em outro caso, esta dificuldade também aparece evidenciada pela ausência de um técnico de referência do próprio serviço, bem como pela intolerância dos profissionais do CAPS com os recorrentes pedidos para realização do exame de HIV.

Eis a pergunta que não quer calar... "será que estamos dispostos a acolher a loucura em nossa vida cotidiana de fato ao afirmarmos que lutamos por uma "sociedade sem manicômios", ou apenas domesticá-la, conferir-lhe mais uma identidade, mortificar o seu potencial disruptivo ou de desterritorialização?” (Dimenstein \& Alverga, 2005, p. 53).

Entende-se que o CAPS produz subjetividades institucionalizadas, normatizadas, manicomiais, confirmando-se pelo modo como todos se referem ao lugar da medicação no projeto terapêutico, e aparece nos discursos dos familiares e até mesmo da equipe técnica.

Ela disse pra mim que, disse que, que me prefere ver morrendo de sono, sem agüentar fazer quase nada, do que agüentando, movimentando, fazendo as coisas, e tudo e nervosa. "É pior", ela falou. Melhor tomar certinho o remédio igual ela quer e ficar calma, mas o pior é que tá precisando da gente também Luana (sic).

A contenção química faz com que a subjetividade seja "eminentemente silenciada, em nome do pragmatismo e da razão instrumental (...). O delírio como obra e produção específica da loucura é silenciado pelos circuitos bioquímicos do sistema nervoso" (Birman, 2002, p. 19). A crítica ao uso do psicofármaco não implica em seu abandono, mas na problematização do seu lugar como um recurso terapêutico utilizado após uma avaliação mais ampla do processo apresentado pelo usuário e articulado com outras propostas terapêuticas. O caráter de denúncia do discurso citado evidencia o esquadrinhamento do desejo e a mortificação da experiência delirante que a medicação tem assumido historicamente. Entretanto, diante de um sofrimento que é difuso e abstrato, culturalmente há uma legitimação do uso da medicação, que afirma a existência de doença e oferece cura e normalidade, conferindo-lhe um grande poder. O discurso de um familiar "Será que essa medicação não vai resolver o problema dessa menina, não normalizar 
a mente dela?" denota a busca por respostas prontas, objetivas e claras.

A medicação - pílula de Deus aparece em alguns discursos legitimada por explicações religiosas:

\begin{abstract}
Abaixo de Deus, vem o tratamento também né? As medicações e todo tratamento que envolve. (...) Deus criou o médico, criou a medicação, deu a inteligência ao homem pra fazer a medicação, a inteligência ao médico pra né, pra nos examinar e tudo. Então eu creio que Deus tá no meio disso aí também (sic).
\end{abstract}

Todavia, com esta prática, coexistem outras propostas terapêuticas, que abrem a possibilidade para novas experiências, com destaque às atividades festivas que contribuem para o processo de autonomia e inclusão social. A riqueza dos relatos de uma das entrevistadas demonstra o quanto $\mathrm{o}$ CAPS tem se constituído para ela como um modelo de atenção integral, capaz de lidar terapeuticamente com seus delírios, medos, inseguranças, desvios, oferecendo atividades terapêuticas, como teatro e oficina de boneca, nas quais ela se implica de modo a ressignificar sua experiência de sofrimento. Além disso, coloca que o CAPS devolveu-lhe o sentimento de ser "gente", de pertencimento ao mundo, como espaço sagrado, onde se sente amparada, segura, acolhida e estimulada a desenvolver várias potencialidades artísticas. Aponta um movimento instituinte do CAPS, analisador que retira o serviço do funcionamento padrão e homogêneo, demonstrando a potência para reavaliar suas práticas, com o propósito de contribuir para o processo de melhora de seus usuários, conforme apareceu nas discussões sobre projeto terapêutico.

No grupo focal, a equipe anunciou um processo de mudança que atravessa o fazer da clínica psicossocial, revelando a busca por uma maior autonomia de gestão em relação à secretaria municipal de saúde, como a aposta na cogestão com os usuários e familiares, tendo sido favorecido pela participação do curso de especialização em saúde mental ${ }^{5}$.

A pesquisa também contribuiu para a problematização das práticas instituídas, principalmente no momento da realização do grupo focal, em que foi abordada a temática da religião. No processo de autoanálise ${ }^{6}$, ficou evidente para a equipe o quanto este tema está presente no cotidiano do serviço e o quanto é silenciado, interditado, por ser um "tabu". O que explode toda uma configuração coletiva de um campo da saúde constituído em oposição ao senso 
comum, aos conhecimentos míticoreligiosos e em relação às práticas religiosas terapêuticas. A equipe reconheceu o seu desconhecimento sobre a dimensão religiosa, tão presente no cotidiano dos usuários, assim como assumiu o preconceito e a dificuldade em lidar com a religião pentecostal. Isso se deve pela compreensão de que ela compete e atrapalha a sua proposta terapêutica, noção que foi reforçada em um único caso em que se sentiram impelidos a buscar a igreja, porque o pastor havia decidido internar no hospital psiquiátrico um usuário do serviço.

Deste modo, a articulação com a religião pentecostal apareceu como um limite, cujo reconhecimento implicou na busca por estratégias de seu enfrentamento, tais como: conhecer as igrejas, fazer parcerias, divulgar $\mathrm{o}$ serviço e, por fim, reconhecer que devem atuar no território, na perspectiva de rede, da qual a religião faz parte.

A perspectiva de encontro que o CAPS anuncia ao abordar a necessidade de trabalho em rede e articulação com o espaço religioso é fundamental para romper com a esquizofrenização gerada nas experiências dos usuários e familiares, que faz com que não se sintam impelidos a falar das experiências no CAPS e na igreja, pelo reconhecimento da desarticulação e disputa de saberes, poderes e projetos das mesmas, sendo esta disputa de saberes e fazeres um analisador importante deste estudo.

\section{Conversações ainda em curso}

Este estudo demonstra movimentos de batalha entre lógicas que, num primeiro momento, apareciam como distintas e divergentes. É com certa tristeza e assombro que nos sentimos tomada pelas vidas cruzadas, pois revelam diferentes modos de captura da diferença, as quais em alguns momentos também nos fisgaram e despontecializaram o percurso, em que, inicialmente, os campos, religião e saúde mental, eram percebidos e vividos como separados, irreconciliáveis, em oposição. Ainda mais quando focávamos o olhar para o pentecostalismo e para o CAPS. Era como se o primeiro fosse visto como o ajudante da ordem e o segundo, o parceiro da loucura.

Havia uma militância e defesa do CAPS por seu movimento instituinte, subversivo, contra-hegemônico, ser capaz de radicalizar a produção de novos encontros com a loucura e com o louco, imbuídos de princípios antimanicomiais, para além do combate 
ao manicômio enquanto espaço geográfico.

O Pentecostalismo, por sua vez, era visto e entendido como o representante do mal, do instituído, da norma, do hegemônico, da lógica manicomial, principalmente por sua concepção de loucura como possessão e sua proposta de exorcismo, reproduzindo um modo histórico de lidar com a loucura no contexto da Idade Média, com requintes contemporâneos.

Entretanto, a experiência nos possibilitou colocar em análise essas concepções e posições, promovendo desestabilizações e desafetos. Ter mergulhado nos interstícios destes campos, nos fez perceber que se tratava de um fogo cruzado entre lógicas diferentes, que perpassam projetos divergentes. O que não se esperava, era encontrar, em vias diferentes, mapas de navegação com roteiros diversos, mas uma mesma direção que manicomializa a vida.

Diante do novo, tivemos que rever os próprios mapas, rever rotas. $\mathrm{O}$ encontro com a Análise Institucional foi crucial para a compreensão de que se trata da análise da religião pentecostal e do CAPS como instituições, vetores que incidem sobre modos de existência, que atravessam e são atravessados por corpos materiais e imateriais, num incessante processo de produção de subjetivação da loucura. Para tal, cada qual com seu manual, com sua munição: a Bíblia com seus mandamentos, de um lado e o manual de CAPS, com as portarias, de outro. Oração e medicação como propostas de salvação.

Enquanto instituições atravessam e são atravessados por movimentos de captura, com propostas de normalização, de cronificação, apropriação da diferença, produzindo subjetividades manicomiais, tornando os loucos prisioneiros do desejo do outro, de dominação, de controle, de contenção, paradoxalmente criando corpos dóceis, disciplinados, e corpos eufóricos e extasiados.

Todavia, as experiências apontam para a necessidade de analisar as instituições em seu cotidiano, onde se tecem práticas e discursos. Para isso, é fundamental recusar olhares totalitários, fechados em si mesmo, que produzem determinações lineares, centrados muitas vezes apenas na dimensão das macropolíticas.

Para que a vida pulse e possamos forjar asas num devir anjo incessante, precisamos lidar com essa intolerável tolerância ao seqüestro do que difere. Para além de defesas pró ou 
contra, de demonizações ou angelizações em relação à religião pentecostal, ao CAPS, afirmamos a importância de promover encontros entre esses campos, principalmente engendrados pelos usuários, analisando possibilidades de articulação, de cuidados compartilhados na perspectiva de rede de atenção integral. Com isso lançamos um convite/ desafio para se experimentar um pensar e agir crítico, ético, estético e político que tensionem os processos de institucionalização do CAPS, da religião, da loucura e de nós mesmos.

Para tanto, acreditamos que este trabalho abre para que novas experimentações, apontando para a importância de se adentrar também no campo religioso para a desterritorialização dos territórios de referência.

Por fim é preciso apostar no liame entre o humano e o mundo, na potência e afirmação da vida, dos desafios que os modos de existência contemporâneos engendram.

\section{Notas}

${ }^{1}$ De acordo com a Política Nacional de Saúde Mental, proposta pelo Ministério da Saúde (Brasil, 2004), os CAPS se dividem em: CAPS I - população entre
20.000 e 70.000 habitantes; CAPS II população entre 70.000 e 200.000 habitantes, ambos com atendimento de segunda à sexta, das $8 \mathrm{~h}$ ás 18h; CAPS III - população acima de 200.000 habitantes, com funcionamento $24 \mathrm{~h}$, inclusive em feriados e fins de semana; CAPS i - atendimento a crianças e adolescentes; e CAPS ad - atendimento à usuários de álcool e outras drogas.

2 Tem como características a manifestação de um Deus vivo, privilégio da experiência religiosa individual, capaz de engendrar visões, profecias, glossolalia (falar em línguas estranhas) e a inspiração, através do exercício dos dons do Espírito Santo. As seguintes igrejas fazem parte do Pentecostalismo: congregação Cristã (1910), Assembléia de Deus (1911), Igreja do Evangelho quadrangular (1951), O Brasil para Cristo (1955), Deus é Amor (1962). Já as igrejas que foram fundadas a partir das últimas décadas, as neopentecostais, são constituídas pela Igreja Evangélica pentecostal Cristã (chamada também Igreja Bom Jesus dos milagres), Igreja Rosa Mística, Igreja Universal do Reino de Deus (1977), igreja internacional da Graça (1974), Igreja Casa da Bênção (1974), entre outras (Andrade, 2003).

${ }^{3}$ A observação participante nos cultos e práticas das igrejas pentecostais 
frequentadas pelos usuários do estudo foi pensada como estratégia metodológica, mas não foi possível devido a curta duração do mestrado.

4 Gostaria de registrar o profundo incômodo e discordância com o fato de ter que selecionar usuários "sem crise", como orientação ética das pesquisas em saúde, por entender que a crise é um momento que explode toda uma configuração coletiva, de uma riqueza ímpar...

${ }^{5}$ Realizado pelo IPUB/ UFRJ, fruto de um convênio entre a secretaria municipal de saúde e o Ministério de Saúde.

6 Esse processo de autoanálise é realizado no interior do próprio grupo e pelo próprio grupo, o que permite aos sujeitos participantes avaliar as condições nas quais estão inseridos e buscar soluções para seus problemas. Deste modo, o processo de autoanálise é simultâneo ao processo de autoorganização, uma vez que exige que o grupo se reposicione diante das novas demandas que irão emergir. Esse processo não prescinde, contudo, da figura do expert, mas deve prescindir da postura centralizadora e dominante do expert. "Para tanto, é de fundamental importância que os experts tenham uma reflexão epistemológica sobre as formas como o conhecimento pode se produzir através da interação com o senso comum. É fundamental que estabeleça uma relação de transversalidade, integrando-se ao movimento de autoanálise e autogestão do grupo e colocando seu saber a serviço do mesmo" (Baremblitt, 1996, p.2).

\section{Referências}

Altoé, S. (Org.). (2004). René Lourau: analista institucional em tempo integral. São Paulo: Hucitec.

Amarante, P. (1995). Loucos pela vida: a trajetória da reforma psiquiátrica no Brasil. Rio De Janeiro: Ed. Fiocruz.

Andrade, M. M. (2002). Possessão como loucura - a noção de saúde e doença mental na igreja universal do reino de deus e sua respectiva proposta terapêutica. Dissertação (Mestrado em Sociologia). Universidade Federal da Bahia, Salvador/ BA. Antoniazzi et al.(1994). Nem anjos nem demônios: $\quad$ interpretações sociológicas do Pentecostalismo. Petrópolis: Vozes.

Baltazar, D. V. G. (2003). Crenças religiosas no contexto dos projetos terapêuticos em saúde mental: impasse ou possibilidade. Dissertação (Mestrado na 
Fiocruz/ENSP), Rio de Janeiro/RJ.

Baremblitt, G. (1996). Compêndio de análise institucional e outras correntes. Rio de Janeiro: Rosa dos Tempos.

Bichuetti, J. (2005). Sobre a crise. Uberaba: Fundação Gregório Baremblitt.

Birman, J. (2002). A psicopatologia na pós-modernidade. In: $O$ mal-estar na atualidade: a psicanálise e as novas formas de subjetivação. Rio de Janeiro, RJ: Civilização Brasileira.

Brasil. (2004). Saúde mental no SUS: os Centros de Atenção Psicossocial. Brasília: ministério da saúde. Secretaria de atenção à saúde. Departamento de ações programáticas e Estratégicas.

Dalgalarrondo, P. (2006). Relações entre duas dimensões fundamentais da vida: saúde Mental e religião. Revista Brasileira de Psiquiatria, São Paulo, vol. 28, 177-178.

Deleuze, G. (1992). Conversações. Editora 34, Rio de Janeiro.

Dimenstein, M. \& Alverga, A. (2005). A loucura interrompida nas malhas da subjetividade. In: Amarante, P. (coordenador). Archivos de saúde mental e atenção psicossocial. Rio de Janeiro: Nau.

Espinheira, G. (2005). Os limites do indivíduo: mal-estar na racionalidade: os limites do indivíduo na medicina e na religião. Salvador: Fundação Pedro Calmon, Centro de Memória e Arquivo Público da Bahia.

Fonseca, T. M. G. (2004). O desejo de mundo: um olhar sobre a clínica. $\begin{array}{lll}\text { Psicol. } & \text { Soc., } 16 \quad \text { (3), Porto }\end{array}$ Alegre, set./dez.

Foucault, M. (2005). História da Loucura. São Paulo: Perspectiva.

Geertz, C. (1978). A interpretação das culturas. Rio de Janeiro: Zahar Editores.

Guattari, F. \& Rolnik, S. (2000). Micropolítica: cartografias do desejo. 6a edição. Petrópolis: Editora Vozes.

Lavrador, M. C. C. (2006). Loucura e vida na contemporaneidade. Tese de Doutorado. Universidade Federal do Espírito Santo, Brasil. Machado, L. M.; Lavrador, M. C. C. \& Barros, M. E. B. (Orgs.). (2001). Texturas $\quad d a \quad$ psicologia: subjetividade e política no contemporâneo. São Paulo: Casa do Psicólogo. 
Montero, P. (1985). Da doença à desordem: a magia na umbanda. Rio de Janeiro: Graal.

Neves, C. A. B. \& Josephson, S. C. (2001). A crítica como clínica. (pp. 99-108). In: Machado, L. M.; Lavrador, M. C. C. \& Barros, M. E. B. (Orgs.). Texturas $d a$ psicologia: Subjetividade e política no contemporâneo. São Paulo: Casa do Psicólogo.

Passos, E. \& Barros, R. B.(2000). A construção do plano da clínica e o conceito de transdisciplinaridade. Psic. teor. e pesq., jan./apr., 16 (1), 71-79.

Pelbart, P. (2001). Da clausura do fora ao fora da clausura. São Paulo: Brasiliense.

Rabelo, M. C. (1993). Religião e cura: algumas reflexões sobre a experiência religiosa. Cadernos de Saúde Pública, Rio de Janeiro.

Redko, C. (2004). Vivendo a primeira experiência da psicose através da religião. In: Leibing, A. Tecnologias do corpo: uma antropologia das medicinas no Brasil. RJ: Nau Editora.

Silveira, L. (2008). Para além de anjos, loucos ou demônios: um estudo sobre modos de subjetivação da loucura, a partir das experiências religiosas de usuários de um CAPS, nas igrejas pentecostais, em um município no interior da Bahia. Dissertação. (Mestrado em Saúde Coletiva). Instituto de Saúde Coletiva, Universidade Federal da Bahia, Salvador, Brasil.

Stadtler, H. (2002). Conversão ao pentecostalismo e alterações cognitivas e de identidade. Revista de estudos da religião. PUCSP, $\mathrm{n}$ 2, 112-135.

Vasconcelos, E. M. (2006). (Org.). A espiritualidade no trabalho em saúde. São Paulo: Hucitec.

Luana da Silveira: Psicóloga UNISC, Especialista e Mestre em Saúde Coletiva - ISC/UFBA, Doutoranda em Psicologia Social-UERJ, Consultora HumanizaSUS - Ministério da Saúde. E-mail: 1uanadasilveira76@gmail.com

Mônica de Oliveira Nunes: ISC/UFBA, Médica, Mestre - UFBA, Ph. D - Universidade de Montreal. E-mail: nunesm@ufba.br 